\title{
RELOCATING OR AGEING IN PLACE? A STORY OF HOUSING MODIFICATIONS IN RURAL, NZ
}

\author{
Tania Smellie and Linda Robertson
}

\section{INTRODUCTION}

As the New Zealand population grows older, there is a trend toward increasing proportions of older New Zealanders living in small towns or rurally (Statistics New Zealand, 2008). Older adults are moving to small towns or rural areas as they age to be closer to family (Burholt \& Dobbs, 20I2), or to enjoy the lifestyle (Provencher, Keating, Warburton, \& Roos, 20I4) or to reduce living costs. Others have lived in small town New Zealand or in rural areas for their entire life and are choosing to age at home (Fraser et al., 2005). Also there are a disproportionate number of Maori living in rural New Zealand with a high proportion of those over 60 years old living in rural and small-town areas (Rural Expert Advisory Group to the Ministry of Health, 2002).

It is a well-known fact that people are living longer than ever before. This has led to a growing population living with a long-term disability, who are increasingly choosing to remain at home (Davey, 2006; De Jonge, Jones, Phillips, \& Chung, 201 I). In New Zealand, 96 per cent of people with a disability live in their own home (Statistics New Zealand, 2014). For people with a disability, their physical environment can have a significant impact on their independence and participation in society (Iwarsson, Ståhl, \& Löfqvist, 20 I 3; Niva \& Skär, 2006). The growing trend of this particular group of people to remain in their home has created an increasing need for housing modifications (Szanton et al., 20I I;Tanner,Tilse, \& De Jonge, 2008). This need will only continue to grow as disability and impaired mobility become more prevalent with an ageing population. For instance, in New Zealand, 59 per cent of people aged 65 or over are living with at least one impairment (Statistics New Zealand, 20 14). Therefore, the New Zealand health system is currently developing policies that focus on supporting these people to remain in their home and to maintain their independence for longer (Ministry of Health, 20I2, 20I6). On a practical level, this means increasing the availability of health care and social support in the community.

One way in which people with disabilities can be stimulated to live in their own home and keep an active life is to modify their home to suit their needs. Such housing modifications are complicated processes that involve making structural or architectural changes to a person's home. Community occupational therapists play a significant role in this home modification process, specifically in the areas of assessment, intervention, follow-up and evaluation of the completed modification (Petersson, Lilja, Hammel, \& Kottorp, 2008) and can thus improve the well-being of the recipients of this process.

Timeframes to access community occupational therapy services, and for housing modifications to be completed, are getting longer. Furthermore, available funding from the Ministry of Health is not matching the increasing demand (Enable New Zealand, 2018). There continues to be a shortfall each year, with regular prompts to limit spending from the organisations administering the housing contracts, as budgets are at capacity for the month (Enable New Zealand, 2018).

This article captures one couples experience of receiving housing modifications in a small rural town in New Zealand and illustrates issues commonly found in rural communities. 


\section{The importance of home and community}

The notion of home is culturally specific. In westernised societies, home is viewed as a place where it is possible to retreat from the eyes of the world to be "ourselves" providing a sense of control (Evans, Wells, \& Moch, 2003). Mallett (2004) argues that a house is not simply a material building but is simultaneously a "home", (frequently defined as "a haven") or a "private place" providing psychological, social, and cultural security. Likewise, in Maori society the concept of Turangawaewae, commonly translated as a "place to stand" is central to ones relationship with the world - where one has rights of residence and belonging through kinship (Mason, 1998). Thus home has different meanings for people, depending on where they have lived, their personal and family history, their social connections and their environmental conditions. (Róin, 2015).

Older people often have strong emotional bonds not only to their homes but also to the wider community. They commonly spend time with friends and participate in family life outside of the home as well as devoting a significant amount of their time to voluntary organisations such as clubs, churches and local schools (Hocking, 20I4). Community involvement and participation in civic duties are significant contributing factors to successful ageing (Cornwell, Laumann, \& Schumm, 2008). For Maori, frequent visits to a marae is associated with higher quality of life (Puāwaitanga, Tapuwae, \& Ora, 2016; Wiles et al., 2017). Thus place attachment involves emotional bonds resulting from a shared history of location (Manzo \& Perkins, 2006). However this can vary between generations. For instance, older adults who have lived in rural areas for a long time have strong connections through generations of involvement in their community but the 'new' rural elderly may not have an equivalent support system (Keating, Eales, \& Phillips, 2013).

\section{The housing situation in New Zealand and the need for complex housing modifications}

Currently, in New Zealand the vast majority of older adults live in single dwellings on large sections, some distance from key services, either within an urban, semi-rural or rural setting (Amore, Viggers, Baker, \& Howden-Chapman, 20 13). Most of these houses were built approximately fifty to eighty years ago, when there was much less awareness of the need to make sure physical accessibility, independence and safety for older adults and persons with disabilities (Mclntosh \& Leah, 20 17). Even today, few building requirements or incentives exist to promote/enforce the building of homes which incorporate attributes which make them more accessible and/or suitable for older adults (Mclntosh \& Leah, 2017).

Modifications to homes can have many benefits. They can help people live independently; enable them to remain in their home, prevent hospital admissions or allow for an early discharge from the hospital (Ministry of Health, 2016). Complex modifications such as the installation of a wet area level access shower or the installation of a ramp or platform lift can have a significant positive impact on a person's quality of life and well-being.

There are a number of issues unique to New Zealand that make complex housing modifications more challenging to facilitate locally. This includes the wide geographical area that needs to be covered, the variations between urban and rural New Zealand, isolation and remoteness, the limited experience among builders and other key team members to design and implement successful modifications at a region level, reliable access to tradesmen, and finally poor-quality housing, often in poor repair (Buckett, Marston, Saville-Smith, Jowett, \& Jones, 20I I; Page \& Gordon, 20 17). This is particularly notable in rental accommodation and in rural New Zealand where families own land and their home, however have not had a consistent income to enable the funding of maintenance. 
This study focuses on housing modifications funded by the Ministry of Health $(\mathrm{MOH})$ in New Zealand. The $\mathrm{MOH}$ supports housing modifications for disabled people of all ages to help them to remain in or return to their home so that they can continue to live as independently and safely as possible (NZ Ministry of Health, 20 I4).This funding is limited and there are specific criteria which govern who receives it and how it is used. A significant portion of the housing modification funding under the Ministry of Health umbrella is allocated to people over the age of 65.

\section{METHODOLOGY}

This study used interpretive phenomenological analysis (Smith, Flowers, \& Larkin, 2009) to capture the stories of people who received housing modifications funded by Ministry of Health. The aim was to examine the effects of housing modifications on the occupations and roles of the recipients, to understand the support they received, and to make recommendations for policy improvements. This article presents the story of James (pseudonym), who lives in a small rural town. It is his explanation of becoming disabled and then receiving housing modifications. It is also his wife's story (Anne - pseudonym) about this process. The interviews were conducted before, and after the housing modification was completed ( 8 months apart). The interviews were semi-structured, narrative interviews. Key questions that formed the basis of the interview were:

\section{Pre modification:}

I was wondering what a good day is like for you.

Tell me about how you feel about your days.

Has your life changed, or

Have the things that you do changed?

\section{Post modification:}

How has the modifications affected what you do in your daily life?

How did you feel after receiving your modifications?

Please comment on the timing of the completion of the modification (e.g. was it about right or too late?)

\section{BACKGROUND INFORMATION}

James and his wife Anne had semi-retired to the region when they were in their early fifties. Both had worked until they reached retirement age in local business. James was actively involved in his local community and lived with his wife in a one bedroom council flat.

James was referred for housing modifications after returning home when he became an amputee. He had his first leg amputated above knee after an acute episode of septicaemia. This occurred as an emergency surgery. During this case study James became a double amputee (above knee). His second leg was amputated above the knee I year later.This was a planned surgery. James was transferred to a large tertiary hospital for both surgeries', returning to his local regional hospital for stump management, inpatient rehabilitation, and community reintegration. Following the second amputation James received extensive modifications to his bathroom (wet area level access shower, new handbasin, toilet and door widening) and to the entrance to his home (aluminium ramping). 


\section{FINDINGS}

\begin{tabular}{|l|l|}
\hline Stage & Themes \\
\hline Pre-modifications & \\
\hline Pre-modifications & Respite vs prison \\
\hline & \\
\hline Post-Modifications & \\
\hline Post-modification - initial & A sense of relief, gratitude, hope and optimism \\
\hline Post-modification & Making sense of unanticipated outcomes \\
\hline Post-modification - later & Reflection \\
\hline
\end{tabular}

Table I.Themes.

\section{Pre-modification interview}

The pre-modification interview has been organised into one major theme that demonstrates the quandary of not knowing how a housing modification will contribute to his life. The three themes in the post modification summary illustrate both the value of the modifications as well as the questions that it raised for James and Ann. Table I. Captures the themes.

\section{Respite vs Prison}

James and Ann did not associate potential difficulties with James's returning home until his discharge from the hospital came closer. James spoke about being in the hospital, preparing to go home, and talking with the ward's social worker about what his needs were going to be upon discharge.

James: There is no way I am going to get into my unit as we have steps, and my bathroom..., well, my wheelchair won't even fit through the door.

James spoke about how he wanted to be at home. He saw this as his right. He saw his home as the place where he felt safe, where he could "be" and "do", and where he could get well, if sick. It was where he belonged. He felt that there was no valid alternative. Continuing to live at home, in their home, was his normality.

James and Ann also talked about choosing their current home based on their long-term needs.

Ann: Our previous home was a lot larger, with a fireplace. A standard weatherboard three-bedroom home, with a section. James [was] unwell for a few years before his amputation. We were struggling to keep the section, and collect the firewood so we could heat the place. We used to go along to the beach and collect driftwood. So, we downsized to our small flat in a block of pensioner flats.

A significant period of time passed (at least 12 months for James) as him and Anne continued to make do within their house. Living in the unmodified house, with a significant disability, meant that the environment had the potential to become quite negative, and potentially toxic.

James: Well, I'm retired, and that's it. I'm basically home-bound, and I look out the window all day. There is nothing out there for me. 
For James, their home environment was far from being right for his level of need. At times, the way they were doing things was unsafe and quite inappropriate. Their issues included inadequate equipment, poor temporary solutions and insufficient support while waiting for their housing modifications.

Ann and James found that the temporary solutions in place were not sustainable solutions. For example, they were not happy about the carer who came to their home for support.

James: We tried having a carer come in to help me with my morning cares, so Ann could have a break. But the agency was useless. They never sent the same person. Half the time the person they sent didn't know what they were doing. Often nobody would turn up. We would wait around for them, and then Ann would need to do it anyway.

The equipment solutions (commode chair for use in lounge, and temporary ramp) would have been suitable for 2-3 months, but they were in place for close to 2 years. James had to complete most of his personal care in the lounge of the couple's small one-bedroom flat because he could not get into the bathroom.

Ann: So, when he wants to pee-pee, he's got the bottle there, and, as he said, if visitors come l've got to take him out of the room. And for the commode - it's always done in the lounge here 'cause we've got no [other] option for him to go. So that's frustrating.

James: I haven't had a shower for [9] months. Because I can't get into the bathroom. Thus, I have bed baths. Anna washes me using a sponge while I lie on our bed. It isn't pleasant.

Going out was hard for James and Ann because of poor equipment and poor environment. Over time, this became very tiring for both James and Ann.

James: Well, the main thing is getting in and out of the car. We've had a little ramp built by a friend for the front door, so we can get to the car. I don't have much of [a] problem getting out of the wheelchair into the car, but it's still a hassle [as the ramp is very steep].

Ann: Yeah, but it's also maybe 'cause that thing's heavy, it is difficult to get you down the ramp in it because it doesn't move very well. The wheelchair gets stuck in the gravel, and I find it hard to push you in it, and then I have to try and lift it in the boot to go out.

James: And if it's raining it's a no-no 'cause you just get drenched.

Ann: 'Cause it takes so long to get him in the car.

From the way James and Anne talked about being unable to get out and about regularly, it becomes apparent that their home started to feel like a prison.

James: I just sit looking out at the world. There is nothing here for me.

Although James engaged in daily conversation with his wife and used media (internet, newspaper, phone) to maintain a relationship with the outside world, he experienced the psychological consequences of not being able to get out of their home and do activities. Both James and Anne reported feeling excluded from life, feeling isolated. They had lost their connections to others in the outside world and found being physically isolated from others extremely taxing. The psychological consequences were severe for James especially. Both of them felt alone, became depressed and lost the motivation to go out. 
The time spent waiting was clearly difficult for James and Anne as each of them spoke about how they wanted to know that the modifications were a possibility much sooner in the process.

Ann: Our main thing is that we have both been angry about the time it has taken, because of how we've got to handle things here with James.

James: Yeah.

Ann: But it's the time lapse that's just about pushing us both over the edge trying to deal with this time.

Not knowing exactly when the modifications were going to be done meant that there was no end in sight.

Ann: Until we know when it's going to be done. It's not good trying to prepare to do something now when it could be another couple of months off. It could be next week, so until we know we're not doing anything.

James: Mm, could be next year.

Ann: Oh, don't even think that! They'll be locking me up in a white jacket if it's that long.

What was obvious from the interview with James and Anne was that they felt stuck and started to have negative feelings about theire home. After a significant wait James and Ann were contacted and the housing modifications were eventually done.

\section{Post-modification}

The completed modifciation included:

- Bathroom - the installation of a level access wet area shower, wheelchair accessible toilet and handbasin, and door widening into the bathroom.

- Door widening - between the lounge and bedroom.

- An aliuminum ramping solution at the front entrance

\section{A sense of relief, gratitude, hope and optimisim}

For James, just being able to go and do simple everyday tasks by himself, in the right room, was truly an amazing experience, after what he and Ann had coped with for so long. The modified bathroom meant that Ann no longer needed to be James's carer at every level and manage all aspects of his personal activities of daily living. It meant that James could do at least some of his bathroom-related tasks himself. For James and Ann, the changes to their bathroom automatically brought some degree of normality back into James's life, and into their relationship.

Ann: Well, now, you know, he wheels himself in now and will clean his teeth and wash his face, and do his hair in there now,

James: Yeah.

James: So, it's so much different.

Ann: And just to go and clean your teeth, eh babe?[...][Before] he'd have to spit in a bowl, and I had to clean it up.

The modifications seemed to bring about some peace. Ann and James described a greater sense of calm at home since having their bathroom modifications completed. 
James: Having the bathroom done has changed things for the better, although there are still big gaps in our lives. Things are now easier at home for both of us, as we don't need to be planning all of the time just to do simple everyday tasks like clean my teeth. Therefore, we find that we are both more relaxed.

\section{Making sense of unanticipated outcomes}

At a superficial level, James seemed to be managing well within the home. However, a deeper conversation with Ann and James revealed that his day-to-day reality was very different. James had not been out of the house for many months except to get his second leg amputated and to have respite care at a local aged care facility for a week when his modifications were being completed.

James: I didn't like to go out because I lost my confidence and people stare at you, and it is just physically too hard on Ann, for us to go out together. We have tried.

He had suffered several knock-backs throughout his journey. He had not gained much control since he had left his home in an ambulance 3 years ago, and had developed a profound sense of hopelessness. Except for the intervention leading up to the housing modification and a period of hospital-based rehabilitation during which he had excelled in an environment that was both accessible and very usable, James had had no community-based input from the community rehabilitation team.

Ann: He did really well in hospital, earned himself a gold star, but that environment was accessible. After rehabbing, it was more a self-confidence thing because he would transfer confidently and go in the bathroom with confidence in hospital, but it was outside that little comfort zone that he lost all his confidence.

James: If I had been supported once I got home to get back out into the community, it might have been different.... [l] may not have got so depressed...

James talked about how he felt that people did not see community occupational engagement as an essential part of a person's day-to-day life.

James: Doing things like getting outside for some fresh air or sitting watching the children play rugby on the backfield is seen as not an essential part of living. Everything is focused on meeting my basic needs with support. Nobody talks about what I may like to do myself. Or what I would like to do outside of this unit.

James and Ann did not have the skills or the appropriate resources to manage the day-to-day life with James living as a double amputee in a wheelchair outside of his immediate environment. When asked if going out was more important than having a modified environment, James responded:

James: Yeah, things you normally do. Just because you've lost your bloody legs. I haven't lost my hands or anything, or brain. That is just so frustrating.

James found it difficult to get about both inside and outside of his home. This significantly affected his ability to participate actively.

It was physically not possible for Ann to push James around the village in his wheelchair, as had been suggested by the hospital as a way of getting out together. And since James could no longer get into or out of their own car, they had to use a mobility taxi to travel distances.

James: I still cannot get in that car, will never be able to.

Ann: So, we've paid for a taxi, a mobility taxi, if we've got to go out anywhere. 
James: So, if we decided to go out anywhere, you've got to add another 50-odd dollar on there, going out.

To be able to live the life they had hoped for prior to the modifications, James needed further changes to be made to their home environment and additional equipment to be supplied.

In addition to further equipment and modifications, James and Anne were also asking for more "people" resources. They wanted support from someone with the appropriate knowledge instead of "battling away" on their own. In other words, they were asking for access to counselling and psychological support, and this 'not instead' of but 'alongside' the community-based services that helped them develop the skills they needed to manage their dayto-day lives.

James got so isolated that his caregiver was concerned and initiated a referral for a Mental Health Assessment. After 3 years of being isolated at home, he was now severely depressed. As a result of the assessment, he began to receive mental health services, including a weekly companionship service. As Anne explained:

James now has a support worker coming in regularly. The idea is that the support worker will take James out to do different activities in the immediate community.

James interjects by explaining:

Well, we've been to McDonald's for ice cream. We've been to look at all the shops and that up north. We went to the hotel and had a beer, and that's it.

Ann explained the importance of this:

.... it was at least 4 years since he'd been into a bar. So, he enjoyed that, so the guy took him for a walk up here to one of the bars, and they sat there, and they had a drink and a yak together.

The focus of this service was to get him back into the community. But the additional support would not be of use until the modifications were made.

Ann: Yeah, that's why I say there are two sides to this. If we had him from day one, it would've been marvellous, but to me, it was still more important to get that .... to get the bathroom modifications for hygiene reasons done first.

Ann was aware that James's recovery was going to take time, and that an important part of this involved being able to get him out of their flat regularly, and actively 'doing' again. Having George coming in every week was effective but Anne added:

All we've got to get done now is organise and try and get this van. [...]Mm. Just even to say right, come on, we're off to Napier, we'll go and have lunch at the beach or something. Even just to do that and zoom down the path and off we go.

James: Yeah.

Ann: 'Cause he gets really down at times, that if I go out it's always just on your own and that was it. So just for both of us, get in the car and just go.

\section{Reflection}

In the end James loss of occupation remained significant with many significant consequences in the long term. Anne could see a time in the not too distance future that moving into a care facility was going to be James's reality. 
Ann: Off the record, if James loses his transfer because our flat is not big enough for the equipment he needs to assist [him], we will either need to shift, or he will need to move into care.

Ann: We are now in a far worst situation than at the being of this process. We believe that we needed to be better informed at the beginning of the process about James long term needs and the limitations of this property. At the beginning if we had known how long the process was going to take we would never had chosen to modify this house. Three years is just too long when you are our age. We lost too much through this process - our identity, our dignity, and the opportunity to be part of our families' lives. James became a shell of himself. I became his full-time carer.

\section{DISCUSSION}

Home had become a negative environment because it restricted the amount of control the participants had in their lives and because there was uncertainty around when the changes might occur (Aplin, de Jonge, \& Gustafsson, 2015; Sixsmith \& Sixsmith, 2008). Home was becoming a place that was "toxic" or poisonous - maybe not physically, but mentally. Initially the situation might remove a part of one's dignity and eventually might affect both physical and mental health. It may lead to sleepless nights, high level of stress that can cause headaches, low mood, upset stomachs, and reduced tolerance for others. This study showed that James and Anne did get to the point where both their physical and mental wellbeing was affected. The place that had been 'home' had become mentally and physically challenging, if not debilitating. For James and Anne the experience of being at home while waiting for modifications was more akin to that of 'a prison and a place of terror' rather than the idealised concept of home as a 'haven or place of love' (Golant, 20I5)

The housing modifications enabled the efficient performance of self-care activities and, whether assisted or not, appeared to provide a foundation from which to expand the occupational lives of the participants (Thordardottir, Fänge, Chiatti, \& Ekstam, 20 I 8).

However, this initial positive response was then superseded by the reality of incomplete solutions and partial enablement. This concurs with the literature which describes the challenges often faced after housing modifications (Aplin et al., 20 I 5; Fänge, Oswald, Gitlin, Iwarsson, \& Wahl, 2009). Most problems arise from having a wrong solution for the level of need, such as modifications not meeting the long-term need, recipients not having the level of skill to enable independence inside and outside of the home, recipients being limited by a lack of transport, and the 'right' mobility solution not being in place. A recent qualitative analysis of the decision-making processes surrounding housing modifications concluded that clients expect the intervention to not only facilitate independent activity, but also to achieve more subjective outcomes, such as freedom and the ability to self-initiate (Thordardottir, Ekstam, Chiatti, \& Fänge, 2016). For James, the level of expectation for the positive effects of the modifications were not always realised over the longer term. This may be the result of insufficient and/or untimely housing modifications, for example by neglecting to modify other parts of the home despite the participant having expressly requested such need in the initial stages of the intervention, as highlighted in other recent studies (Granbom, Taei, \& Ekstam, 20 I 7).

For James and Anne the housing modifications did not deliver the expected gains they had anticipated, the battle to engage in daily activities continued. This had a marked impact on James wellbeing. Over time, unmet housing modification needs are inescapable as a consequence of a progressive decline in health and wellbeing. Nevertheless, the reality that unmet needs arose early in the process for James is of significant concern and indicates that the needs assessment was not complete/robust. Similar results have been found in an earlier Swedish study (Ekstam, Fänge, \& Carlsson, 2016). It is a challenging task to facilitate a housing modification that is both viable and flexible when the recipient's need shifts over time. However, this study indicates that recognising the broader (and sometimes transient) influences on a particular situation is likely to have a postive influence on both performance and participation for the recipient. It is therefore important to understand dynamic interplay between these influences if a sustainable solution is to be found. 


\section{Home vs control}

This study has shown that remaining in one's home and community is not likely to be the optimal situation for everyone. While remaining in the same neighbourhood and dwelling may have beneficial effects for some, there is little rigorous research regarding the costs and benefits of doing so. Furthermore, some scholars (Golant, 20 I5; Wilkinson-Meyers et al., 2014) have raised concerns about the different experience of being 'in place', noting that not everyone is able to live safely, independently and comfortably as proposed by the World Health Organisation. This is exemplified by a growing recognition that 'ageing in place' is not always desirable and that being "stuck" in place (Golant, 20I5) may lead to negative outcomes in health and wellbeing.

James's experience of being in place post modification was negative, and eventually lead to him and Ann to considering the option of relocation. There appears to be a number of parallels between what Ann and James identified as they considered a move to a different home and Golant's (20I I) work on voluntary relocation. Golant suggests that voluntary residential relocation is only considered after the person has tried to adapt his or her situation through assimilative and accommodation changes. In addition, moving will not occur unless it is perceived as a feasible option based on physical, psychological, social factors and in particular, financial resources. Furthermore, the person or couple must believe that relocation will result in improved outcomes such as increased feelings of mastery and comfort. This involves expectations that the act of moving will not exceed their threshold for stress or negative emotional experiences (Golant, $20 \mathrm{ll}$ ). James and Anne described that they would have chosen relocation over staying in place initially if they had realised that relocation would have resulted in feeling more in control. Simply stated, place does matter as much as feeling in control. Further research is required to address this gap in our understanding of how to support people when they are choosing to modify or relocate.

Most people in the older age group recognise that they need to think about how to make home life easier when moving into older age (Golant, 20 I I). In Golant's study there was a planned transition when the participants began the process of organising their affairs to move into retirement. During the planned transition the participants reported that they considered when they were going to retire, where they were going to live, and how they were going to meet their living costs. Consideration was also given to the location of their home relevant to key services (e.g. doctor, supermarket, and hospital), the level of maintenance the property would require, and how age-friendly the property was - i.e. single storey, located on a level section, and the number of steps into the home (Golant, 20 I5). James commented on the difficulties they had finding a suitable property to retire to, however they thought they had chosen the right property for their needs. This transition is a critical time for older people and a key opportunity to positively influence the timing of housing modifications.

The interviews also revealed the necessity of having adequate space. James and Anne talked about their need for a space in which to socialise and entertain, but also for quiet areas where they could rest and recharge. In addition, having enough room to store and tidy items is important for people's mental health, as clutter and mess can result in anxiety making it difficult to physically and mentally relax (Davy, Adams, \& Bridge, 2014 The value ascribed to space within the home is integral to how it is utilised and also whether a family member with a disability is included or excluded from that space or area (Buffel, 2017).

\section{Empowerment}

There has been a change in society's expectations as to of what a person living with a disability can expect with regards to quality of life. The disability community has worked very hard to have equal opportunities to participate in meaningful occupations that ensure a good quality of life (Durocher, Rappolt, \& Gibson, 20 I4; Imrie \& Luck, 2014). Furthermore, there is an emphasis on empowering the individual to maintain engagement in meaningful occupations and in their wider community. However, as this study has shown, at the service level there is uncertainty as to how this empowerment can be effectively and continuously delivered. There is a need to do further research on home environments and how these may be modified more effectively and sustainably in order to increase a person's level of participation. 
This is a particular issue for those living in rural areas as New Zealand is aging at a faster rate in smaller towns and rural regions than it is in larger cities. Between 1996 and 2006 alone, the proportion of New Zealanders living rurally that were older than 65 years rose from 8.2\% to $10.1 \%$ (Statistics New Zealand, 2008). The number of older adults in rural areas looks set to increase further in the future as the number of adults in New Zealand over 65 years of age is expected to double in the next 25 years (Statistics New Zealand, 2008). There is the potential for even greater disparities as the population continues to age. Such geographical differences in the number and proportion of older people may also bring challenges for local authorities, DHBs and the private sector to provide more strategic resource that focuses on older adults needs, healthcare, transportation and suitable housing. This will require a national approach with a focus on housing in rural New Zealand. The primary purpose will be to ensure that small town New Zealand and rural New Zealand have housing solutions that will ensure that people have the opportunity to age in place.

\section{CONCLUSION}

Reasoning about whether to relocate or age in place with housing modifications is a complex and ambivalent matter. It is important that the client's voice is heard throughout the process, at all levels, and their individual values are respected. Finally, it is essential to understand the high value that a housing modification holds for individuals who choose to remain in place and experience everyday life as a struggle. Yet as this research found, delays in the referral and delivery systems for modifications and peoples tendency to be reluctant to seek help until they are forced to do so by a crisis, means that help may come too late for many.

Tania Smellie PG Dip OT, BOT is an occupational therapist. As an Occupational Therapist, her postgraduate experience within New Zealand includes time within the District Health Board system; providing occupational therapy intervention in both in-patient, out-patient and community settings, both in physical and mental health. In addition, she has also have spent time working in an NGO and for private organisations, including large aged-care providers. She has worked in clinical roles and more recently operation roles. She also has a diploma in Architecture Design and Technology.

Associate Professor Linda Robinson (10 0000-0003-3086-285I) Linda has been involved in postgraduate teaching for over 10 years. She enjoys opportunities to enter into the student's discussions as they complete their research projects. Such learning opportunities enable her to rethink practice and to extend her knowledge. Her research areas are in clinical reasoning and working with older people.

Correspondence to:Tania Smellie, Otago Polytechnic, New Zealand. Email:Tanz_elizabeth@hotmail.com 


\section{REFERENCES}

Amore, K., Viggers, H., Baker, M. G., \& Howden-Chapman, P. (2013). Severe housing deprivation:The problem and its measurement. Official Statistics Research Series, 6, 82I-831.

Aplin, T., de Jonge, D., \& Gustafsson, L. (20।5). Understanding home modifications impact on clients and their family's experience of home: A qualitative study. Australian Occupational Therapy Journal, 62(2), | 23-13 I. https://doi.org/ I 0. I I I I/ | 440- 630 . 12 I 56

Buckett Ed, N., Marston Ed, N., Saville-Smith, K., Jowett, J., \& Jones, M. (20I I). Preliminary BRANZ 2010 House Condition Survey Report. STUDY REPORT SR (2nd ed., Vol. 240). New Zealand: Branz Ltd.

Buffel,T. (2017). Ageing Migrants and the Creation of Home: Mobility and the Maintenance of Transnational Ties. In Population, Space and Place (Vol. 23, p. el 994). https://doi.org/I 0. I002/psp. 1994

Burholt, V., \& Dobbs, C. (2012). Research on rural ageing:Where have we got to and where are we going in Europe? Journal of Rural Studies, 28(4), 432-446. https://doi.org/10.1016/j.jrurstud.2012.01.009

Cornwell, B., Laumann, E. O., \& Schumm, L. P. (2008). The social connectedness of older adults: A national profile. American Sociological Review, 73(2), 185-203. https://doi.org/10.1 177/00031224080730020 I

Davey, J. (2006). "Ageing in place": The views of older homeowners on home maintenace, renovation and adaptation. Social Policy Journal of New Zealand, 3(27), 128-141. Retrieved from http://www.msd.govt.nz/documents/about-msd-and-our-work/ publications-resources/journals-and-magazines/social-policy-journal/spj27/27-pages | 28- | 41.pdf

Davy, L., Adams, T., \& Bridge, C. (20I4). Caring for the carer: Home design and modification for carers of young people with disability. Sydney: Home Modification Information Clearinghouse, University of New South Wales Australia. https://doi.org/978-0-73343499-0

De Jonge, D. M., Jones, A., Phillips, R., \& Chung, M. (20I I). Understanding the essence of home: Older people's experience of home in Australia. Occupational Therapy International, 18(1), 39-47. https://doi.org/ I0.1002/oti.312

Durocher, E., Rappolt, S., \& Gibson, B. E. (2014). Occupational justice: Future directions. Journal of Occupational Science, 2 I (4), 431-442. https://doi.org/10.1080/14427591.2013.775693

Ekstam, L., Fänge, A. M., \& Carlsson, G. (2016). Negotiating control: From recognizing a need to making a decision to apply for a housing adaptation. Journal of Housing for the Elderly, 30(4), 345-359. https://doi.org/ I 0. 1080/02763893.20 I 6. I 224788

Enable New Zealand. (2018). Expenditure on equipment and modification services 2017-20/8. Wellington. Retrieved from https:// www.disabilityfunding.co.nz/equipment/equipment-and-modification-services-demand-by-district-health-board-area/ expenditure-by-dhb

Evans, G. W., Wells, N. M., \& Moch, A. (2003). Housing and mental health: A review of the evidence and a methodological and conceptual critique. Journal of Social Issues, 59(3), 475-500. https://doi.org/ I0.1 I I I/I540-4560.00074

Fänge, A., Oswald, F., Gitlin, L. N., Iwarsson, S., \& Wahl, H.W. (2009). The home environment and disability-related outcomes in aging individuals: What is the empirical evidence? Gerontologist, 49(3), 355-367. https://doi.org/ / 0. I 093/geront/gnp056

Fraser, C., Jackson, H., Judd, F., Komiti, A., Robins, G., Murray, G., ... Hodgins, G. (2005). Changing places: the impact of rural restructuring on mental health in Australia. Health \& Place, I / (2), | 57- I 7 |. https://doi.org/ | 0. I 0 I 6/j.healthplace.2004.03.003

Golant, S. M. (20I I). The quest for residential normalcy by older adults: Relocation but one pathway. Journal of Aging Studies, 25(3), 193-205. https://doi.org/10.1016/j.jaging.2011.03.003

Golant, S. M. (20।5). Aging in the right place. Baltimore: Health Professions Press. Retrieved from https://books.google.com.au/books/ about/Aging_in_the_Right_Place.html?id=EH-6rQEACAAJ\&redir_esc=y

Granbom, M., Taei, A., \& Ekstam, L. (2017). Cohabitants' perspective on housing adaptations: A piece of the puzzle. Scandinavian Journal of Caring Sciences, 3 I (4), 805-8 I3. https://doi.org/ I 0. I I I I/scs. I 2400

Hocking, C. (20 I4). Contribution of occupation to health and well-being. In B. Boyt, M. Schell, \& G. Gillen (Eds.), Willard \& Spackman's occupational therapy ( 12 th ed., pp. 72-8I). Philadelphia:Williams \& Wilkins.

Imrie, R., \& Luck, R. (20।4). Designing inclusive environments: Rehabilitating the body and the relevance of universal design. Disability and Rehabilitation, 36(16), |315-1319. https://doi.org/10.3109/09638288.2014.936191

Iwarsson, S., Ståhl, A., \& Löfqvist, C. (2013). Mobility in outdoor environments in old age. Environmental Gerontology: Making Meaningful Places in Old Age., 175-198. Retrieved from http://proxy.lib.sfu.ca/login?url=http://search.ebscohost.com/login. aspx?direct=true\&db=psyh\&AN=20 I3-07285-008\&site=ehost-live

Keating, N., Eales, J., \& Phillips, J. E. (20 I3). Age-Friendly Rural Communities: Conceptualizing 'Best-Fit.' Canadian Journal on Aging / La Revue Canadienne Du Vieillissement, 32(4), 319-332. https://doi.org/ I 0. I 0 I 7/S07 I 49808 I 3000408

Mallett, S. (2004). Understanding home: A critical review of the literature. The Sociological Review, 52(I), 62-89. https://doi. org/ | 0.1 I I I/j. I467-954X.2004.00442.x 
Manzo, L. C., \& Perkins, D. D. (2006). Finding Common Ground:The Importance of Place Attachment to Community Participation and Planning. Journal of Planning Literature, 20(4), 335-350. https://doi.org/ I 0. I I 77/08854 I 2205286 I60

Mason, D. (1998). Whaiora: Maori Health Development (2nd ed.). Oxford University Press.

Mclntosh, J., \& Leah, A. (20 I7). Mapping housing for the disabled in New Zealand. New Zealand Medical Journal, 1 30(I 457), 69-78.

Ministry of Health. (2012). Long-term residential care for older people: What you need to know. Wellington.

Ministry of Health. (2016). New Zealand Health Strategy: Future direction. Wellington: Ministry of Health.

Niva, B., \& Skär, L. (2006). A pilot study of the activity patterns of five elderly persons after a housing adaptation. Occupational Therapy International, $13(1), 2$ I-34. https://doi.org/ 10.1002/oti.21

NZ Ministry of Health. (2014). Equipment and Modification Services Housing Modifications Manual (corrections made to May edition), (September), I-3.

Page, I., \& Gordon, G. (2017). SR380 What is quality in buildings? Retrieved from https://www.branz.co.nz/cms_show_download.php ?id=3a755303 I 5 I dbaf4a9fe04e56f5be968f699 I 633

Petersson, I., Lilja, M., Hammel, J., \& Kottorp, A. (2008). Impact of home modification services on ability in everyday life for people ageing with disabilities. Journal of Rehabilitation Medicine, 40(4), 253-260. https://doi.org/ I 0.2340/I 650 I 977-0 I 60

Provencher, C., Keating, N., Warburton, J., \& Roos, V. (2014). Ageing and community: Introduction to the special issue. Journal of Community and Applied Social Psychology, 24(I), I-I I. https://doi.org/ I 0.1002/casp.2 I7 I

Puāwaitanga,T., Tapuwae, O. N., \& Ora, K. (20।6). Relationships and emotional support in advanced age: Findings from LiLACS NZ, $|-| \mid$.

Róin, Á. (2015). The multifaceted notion of home: Exploring the meaning of home among elderly people living in the Faroe Islands. Journal of Rural Studies, 39, 22-31. https://doi.org/I0.1016/J.JRURSTUD.2015.03.002

Rural Expert Advisory Group to the Ministry of Health (2002). Implementing the primary health care strategy in rural New Zealand. Wellington, New Zealand: Rural Expert Advisory Group to the Ministry of Health.

Sixsmith,A., \& Sixsmith, J. (2008). Ageing in place in the United Kingdom. Ageing International, 32(3), 21 9-235. https://doi.org/I 0. I 007/ s12126-008-9019-y

Smith, J. A., Flowers, P., \& Larkin, M. (2009). Interpretative phenomenological analysis theory and research. London: SAGE Publications Ltd.

Statistics New Zealand. (2008). Urban and rural migration. Retrieved from: http://www.stats.govt.nz/browse_for_stats/population/ Migration/internalmigration/urban-rural-migration.aspx

Statistics New Zealand. (20 |4). 2013 New Zealand Disability Survey, (June), I -30. Retrieved from http://www.stats.govt.nz/browse_ for_stats/health/disabilities/DisabilitySurvey_HOTP20I3.aspx

Szanton, S. L., Thorpe, R. J., Boyd, C., Tanner, E. K., Leff, B., Agree, E., ... Gitlin, L. N. (20I I). Community aging in place, advancing better living for elders: A bio-behavioral-environmental intervention to improve function and health-related quality of life in disabled older adults. Journal of the American Geriatrics Society, 59( I2), 23 I4-2320. https://doi.org/ I 0. I I I I/j. I 532-54 I 5.20 I I.03698.x

Tanner, B., Tilse, C., \& De Jonge, D. (2008). Restoring and sustaining home:The impact of home modifications on the meaning of home for older people. Journal of Housing For the Elderly, 22(3), 195-2 I5. https://doi.org/ I 0. I 080/02763890802232048

Thordardottir, B., Ekstam, L., Chiatti, C., \& Fänge,A. M. (2016). Factors associated with participation frequency and satisfaction among people applying for a housing adaptation grant. Scandinavian Journal of Occupational Therapy, 23(5), 347-356. https://doi.org/I $0.3109 / 11038128.2016 .1139622$

Thordardottir, B., Fänge, A. M., Chiatti, C., \& Ekstam, L. (2018, April 6). Participation in Everyday Life Before and After a Housing Adaptation. Journal of Housing for the Elderly, pp. I- 15. https://doi.org/ / 0. I 080/02763893.20 I 8. I 45 I 800

Wiles, J. L., Rolleston, A., Pillai, A., Broad, J., Teh, R., Gott, M., \& Kerse, N. (2017). Attachment to place in advanced age: A study of the LiLACS NZ cohort. Social Science \& Medicine, 185, 27-37. https://doi.org/ I 0. I 0 I 6/j.socscimed.2017.05.006

Wilkinson-Meyers, L., Brown, P., Reeve, J., McNeill, R., Patston, P., Dylan, S., ... McEldowney, J. (20।4). Reducing disablement with adequate and appropriate resources: A New Zealand perspective. Disability and Society, 29( I0), I540- I553. https://doi.org/ 10.1080/09687599.2014.966803 